\title{
THE ROLE AND SIGNIFICANCE OF HOMEWORK IN INITIAL MATHEMATICS TEACHING
}

\author{
Sead Rešić ${ }^{1}$ \\ Mirjana Bradarić
}

Original scientific paper

Department of Mathematics, Faculty of Natural Sciences, University of Tuzla

Received: 25.11 .2012

UDC: $371.322 .1: 51$

Accepted: 16.01.2013

\begin{abstract}
This thesis elaborates on the role and importance of homework in the initial stages of teaching mathematics. The aim is to determine and analyze the degree of burden on students with homework. The following tasks were performed as a starting point for this research: determining the degree of correlation between the time that student spends on weekly homework and the student's homework amount determinedby the pedagogical norm, determining the level of parents' participation in helping students with homework, etermining the degree of correlation of differentiation of homework with the students' motivation for doing homework. Homework plays an important role in the initial stages of teaching mathematics, and takes up a significant place in the process of studying and teaching mathematics. The results, analysis, and conclusions are presented upon research.
\end{abstract}

Key words: Mathematics, school, homework

\section{INTRODUCTION}

In the history of teaching, the students' relation towards homework has not always been equable, as is not today. In the 'old school', dominated by so-called lectionism, students were burdened with repetition of lessons in order to memorize them. Besides repeating lessons, homework included exercising to acquire elementary skills of reading, writing, calculus. This is why in the old school the character of homework was reproductive. In the new school homework is still present, but its point and character is changing. Not only is it of reproductive character, but it is also productive, i.e. it has the character of independent new knowledge "earning" (Tomić \& Osmić, 2006).
This type of work must have contributed to acquiring the ability of independent work, that is, self-education. Throughout history, homework has accompanied the process of mastering the subject matter. Often, homework was assigned to students to allow them to master certain topics until the teacher comes to their area again. This way, students studied individually and progressed without the help of a professional. A similar manner of knowledge supplementation has been kept even until today, with certain corrections. As the subject matter became more complex through history and demands from students got greater in quantity, the type of homework adjusted to the demands of new subject matter.

\footnotetext{
${ }^{1}$ Correspondence to:

Sead Rešić, Department of Mathematics, Faculty of Natural Sciences, University of Tuzla

Šabana Zahirovića 10, Tuzla, B\&H

Phone: +38761101230

E-mail: sresic@hotmail.com
} 
The very conceptions regarding the need for doing homework, manner of reviewing it, as well as the question whether homework should be included while forming the final grade vary. Today, there is the dilemma about what the child needs, what volume of knowledge, and how much, as well as what, to ask from the child in return, in the form of feedback, which will be done individually at home. Due to this vagueness, there are variations with many teachers, and the question is posed: What is homework, how to assign tasks, what to give for homework, how much to assign, and is homework even necessary? Homework is the student's activity which derives from everyday schoolwork obligations, but is performed outside of schoolwork. It is also possible to provide an answer to the question how to assign tasks. First and foremost, most of the tasks prepared for student's individual work should be textual in nature and contain information from the student's immediate surroundings. The teacher's obligation is to analyze every task with students and provide instructions for work, and precisely that ensures success in teaching.

The question what to give for homework is not difficult to answer, if one bears in mind that everything that was the subject of discussion during previous classes, should also be the subject of individual work. The best policy is to assign tasks which encompass more teaching units.

To the question how much homework to assign, the answer depends on the grade which students are in, the content, structure, complexity of subject matter. Homework is a significant factor in developing student's individuality (including transcribing). The higher the level of interest for mathematics teacher manages to achieve in a student, the more secure they can be that the child will come up with the results on his/her own. This is a great mutual success! If the child is not interested, it leads to him/her being burdened with various demands from the teacher or developing resistance towards school, homework, and generally responsibility about work.

\section{THEORETICAL PROBLEM DISCUSSION}

\section{Introductory mathematics teaching}

Mathematics teaching in the first five grades of elementary school in Bosnia and Herzegovina is called introductory, while the science that studies nurture and education within it is called methodic of introductory mathematics teaching. Every type of methodic, as is the case with that of introductory mathematics teaching, has its own subject of studying, which is mathematics nurture and education in the first five grades of elementary school.

The educational influence of teaching is affected by: the curriculum, students' books and additional materials, school's equipment regarding teaching resources and aids. Mathematics teaching in lower elementary school grades consists of methodical unifying of mathematical knowledge, logical thinking and working-technical agency in the process of continuous pedagogical activity.

Knowledge, thinking and acting are the three basic activity components in general, and this applies also to organized nurture and teaching generations of students. The realization of mathematics classes in lower elementary school grades depends on adequate resolution of the following methodic questions:

- Psycho-physical characteristics of lower elementary school students,

- Aim and tasks of teaching mathematics,

- Specificities of mathematical education. (Markovac, 1992)

\section{Psycho-physical characteristics of lower elemen- tary school students}

Characteristics of psycho-physical age of students from first to fifth grade of elementary school represent a factor which determines the content, methods and forms, teaching materials etc. in teaching mathematics. Being familiar with and appreciating those characteristics presents the precondition of methodic organization in teaching mathematics.

To that end, three most important characteristics of lower elementary school students are presented.

Children of this age react to all forms of influence from immediate surroundings.

This validity applies also to behavior in mathematics classes.

Accordingly, being uninterested in mathematics is not one of psychological characteristics of students. Not reacting in classes is in a certain manner a latent state which should be changed, put into motion and methodically accept in the process of teaching mathematics.

Children of this age explore, they are very emotional, their psychological development is continuous, they learn best when they are active... 


\section{Aim and tasks of teaching mathematics}

The aim of teaching mathematics is to:

- Capacitate students to master elementary mathematical knowledge necessary for understanding events and laws that govern nature and society;

- Contribute to developing mental abilities, forming a scientific outlook on the world and a comprehensive development of the students' personality;

- Capacitate students to apply mastered mathematical knowledge in solving various practical tasks in life;

- Capacitate students to successfully continue their education in mathematics.

The tasks of teaching mathematics are to enable:

- Students to acquire knowledge necessary to understand quantitative and spatial relations and laws in different instances which occur in nature, society and everyday life;

- Students to acquire basic mathematical culture necessary for revealing the role and application of mathematics in various areas of human activity, as well as for successful continuation of education and inclusion in the work market;

- Development of student's ability to observe, perceive and think in a logical, critical, creative and abstract manner;

- Development of cultural, work, ethical and aesthetical habits in students, as well as mathematical curiosity in observing and studying phenomena.

\section{Specificities of mathematical education}

Education is a fundamental pedagogical and didactical category of teaching, comprised of quantity of facts and information, system of knowledge, skills and habits, and basic capabilities and abilities of a personality. Dismantled in this manner, educational value bears a distinctive influence on its very realization in the practice of teaching mathematics in lower elementary school. Education in mathematics is manifested by mediate knowledge about the objective world through numbers, their relations and spatial dimension. From this standpoint, the following should be taken into consideration: differentiation between the terms 'science' and 'mathematics teaching', distinguishable specificities of mathematical education and guidance through mathematics teaching.

Mathematics as a school subject, especially today, in the era of dynamic scientific and technical-technological development, as well as overall computerization, bears immense significance and role in pedagogic and educating the young generation, as well as in preparing it for their future life and work. Mathematics teaching presents a major segment in integral general education and a basis for development of a wholesome student's personality, since it significantly contributes to general students' accomplishments (educational, pedagogic and functional). (http://uciteljitk.com.ba/Npp.pdf; accessed 07/05/2012)

\section{Mathematics teaching layout}

Teaching layout is an official school document prescribed by the appropriate state organ. Mathematics teaching layout determines the number of mathematics classes for the entire academic year. Within the concept of nine-year elementary education is derived as follows: $1^{\text {st }}$ grade has 2 mathematics classes a week, i.e. 68 classes a year; $2^{\text {nd }}$ and $3^{\text {rd }}$ grades have 3 mathematics classes a week, i.e. 105 classes a year; $4^{\text {th }}$ grade has 4 mathematics classes a week, i.e. 140 classes a year; $5^{\text {th }}$ grade also has 4 classes a week, i.e. 140 classes a year.

Framework of mathematics teaching layout for $1^{\text {st }}, 2^{\text {nd }}, 3^{\text {rd }}, 4^{\text {th }}$ and $5^{\text {th }}$ grades in nine-year elementary school

$\begin{gathered}\text { Number of classes per } \\ \text { week }\end{gathered}$
Number of classes per year

\begin{tabular}{cccccccccccc}
\hline No. & $\begin{array}{c}\text { Obligatory school } \\
\text { subjects }\end{array}$ & I & II & III & IV & V & I & II & III & IV & V \\
\hline 1 & Bosnian language & 3 & 4 & 4 & 4 & 4 & 102 & 140 & 140 & 140 & 140 \\
2 & Mathematics & 2 & 3 & 3 & 4 & 4 & 68 & 105 & 140 & 140 & 140 \\
3 & My environment & 2 & 3 & 3 & 3 & 3 & 68 & 105 & 105 & 105 & 105 \\
4 & Music & 2 & 2 & 2 & 2 & 2 & 68 & 70 & 70 & 70 & 70 \\
5 & Art & 2 & 2 & 2 & 2 & 2 & 68 & 70 & 70 & 70 & 70 \\
6 & Physical education & 2 & 2 & 2 & 2 & 2 & 68 & 70 & 70 & 70 & 70 \\
Total & & 13 & 16 & 16 & 17 & 17 & 442 & 560 & 560 & 595 & 595 \\
\hline
\end{tabular}




\section{Mathematics teaching curriculum}

Curriculum is an official school document which prescribes the subject matter that will be studied within a school subject, that is, which knowledge, skills and habits the students should acquire in each grade. The content of mathematics is given as clearly formulated program units, with specified number of classes dedicated to each program unit and with an array of topics which should be divided into subject units for the entire academic year.

In this manner, teaching units are formed for methodical organization of mathematics classes. We will indicate the content (subjects and areas) of the curriculum in nine-year elementary school. (Web source: http://uciteljitk.com.ba; accessed 07/05/2012)

PROGRAM UNITS FOR FIRST GRADE OF NINE-YEAR ELEMENTARY SCHOOL EDUCATION (teaching units)

1.Comparing, assessing and measuring the size of objects

2.Objects in the shape of a sphere (ball), cube, cyl inder and pyramid

3.Flat and curved facets (surfaces), shapes and lines

4.Sets, numbers, relations and operations

PROGRAM UNITS FOR SECOND GRADE OF NINE-YEAR ELEMENTARY SCHOOL EDUCATION (teaching units)

1. NUMBERS

- Summation and detraction in a set of numbers up to 20

- Set of numbers up to 100

2.GEOMETRY

- Objects in the shape of a sphere, cube, parallelepiped, cyl inder, pyramid and cone

- Facets (surfaces) and lines

3. MEASURING AND MEASUREMENTS

- Measuring length, measuring mass, units for measuring liquids, units for measuring time, units for measuring money.

PROGRAM UNITS FOR THIRD GRADE OF NINE-YEAR ELEMENTARY SCHOOL EDUCATION (teaching units)

1. Summation and detraction up to 100

2. Flat and curved facets (surfaces), shapes and lines
3. Multiplying and dividing up to 100

4. Measuring, comparing and assessing

PROGRAM UNITS FOR FOURTH GRADE OF NINE-YEAR ELEMENTARY SCHOOL EDUCATION (teaching units)

1. Numbers in the first thousand

2. Straight line in a plane

3. Summation and detraction up to 1000

4. Circle

5. Multiplying and dividing up to 1000

6. Measuring quantities and sizes

PROGRAM UNITS FOR FIFTH GRADE OF NINE-YEAR ELEMENTARY SCHOOL EDUCATION (teaching units)

1. Numbers in the first million

2. Summation and detraction up to one million

3. Multiplying and dividing up to one million

4. Arithmetic expressions

5. Numbers over one million

6. Set of natural numbers $(\mathrm{N})$ and set $\mathrm{N}^{\mathrm{o}}$

7. Angle

8. Triangle

9. Surface of a rectangle

10. Volume of a parallelepiped (especially cube)

\section{Material conditions for realization of classes}

Basic material conditions are organization of work and provision of class resources, as well as students' out-of school activities. In the analysis of above-mentioned conditions, it is most commonly claimed that they are very bad, since schools are poorly equipped for class realization. This claim is not true, but it is true that available space and resources in many schools are not organized and equipped for mathematics. Therefore, material status of schools cannot be blamed for insufficiently equipped classrooms with teaching resources for elementary mathematics classes. The responsibility lies on the teacher himself/herself, who, in aninadmissibly reduced manner takes their position in the very process. An innovative teacher will animate stu dents to individually make teaching aids and thus create learning and exploring with the very resources they produce and make. For example, by modeling a potato into a parallelepiped, a child will in the best possible way notice the six flat surfaces and six rectangles; to model Roman numerals (numbers) matches can be of assistance. 
Matches can be used to model arithmetic expressions when solving mathematical problems, where we combine and constantly change shapes - this is more practical. It is important to accurately create task models from matches, which will make the exercise warmer even though we will never light the matches. Still, with all that has been said, spatial conditions in our schools are not amiable for realization of 'prolonged students' obligations' in the school classroom. Therefore, especially in mathematics teaching, we must depend on students' activities at home.

Working areas are the school media library and specialized classes.

These conditions are initial necessities for successful organization of mathematics teaching in lower elementary education. A specialized mathematics classroom is not 'a laboratory', but rather a classroom adequately equipped for all subjects in lower elementary education. It also contains implemented instruments for mathematics classes. If methodically well conceptualized, a specialized classroomis suitable for work with a special section of one grade and work with a combined section of multiple grades. Educational role of the specialized classroom is supplemented with the school media library. That room is connected with all classrooms for lower elementary education. It is equipped with all the aids which are used by all the classes of all grades in the school. The term teaching resources and aids refers to a variety of material objects used in learning a particular school subject. In different school subjects and different stages of education, different teaching resources and aids are employed. Even within the same school subject, depending on the age of students, different teaching resources and aids are used. The use of teaching resources and aids depends also on the level and quality of intellectual development of students for whom they are intended.It is also based on the psychological fact that learning is more successful if more components for input of information are included.

Since the beginning of organization of mathematics teaching, there have been efforts to facilitate, rationalize and intensify the process of acquiring knowledge, developing thought process and forming the levels of success necessary for work and life.

The fundamental task of mathematics teaching is development of abstract manner of thinking. However, not one abstraction can appear if there is no concrete image in the consciousness. For lower elementary mathematical imagery, it is necessary to employ appropriate teaching resources. In order to emphasize the methodical value of teaching resources, we will place accent on their characteristics and classification, due to their function in the process of mathematics teaching. Every teaching resource possesses characteristics of importance for methodical intensification of students' activity. Teaching resources should primarily be easily explicable and explicative (i.e. simple enough to explain certain mathematical values and relations in nature and society).

For effective use in teaching, resources should be: accurate by function - mathematical information must be scientifically verified; distinct by form - to induce clear mathematical notions; have a pleasant outlook - their appearance should induce aesthetic emotions; and adequate for use - to be easily demonstrated. For the needs of lower elementary mathematics teaching, there are various teaching resources and aids, which are usually divided into natural and artificial ones. Natural ones are those from immediate surroundings or those which are adjusted by slight reshaping to teaching needs.

Natural teaching resources are, first and foremost, objects in immediate surroundings (desks, chairs, chalk, etc.), then objects which belong to students (marbles, stickers, drumsticks, different fruits, books, pencils, erasers, etc.). All these objects can in certain situations be used in elementary mathematics teaching. Artificial teaching resources are those that are specially constructed and manufactured for the purpose of learning. This group encompasses, for example, plastic slates (triangles, squares, circles), tokens (of various shapes and colors), models of geometrical figures, different gauges (for measuring length, surface, mass, volume, time), graphic aids (drawings, pictures, numerical pictures), geoplan, colored sticks (colored numbers), various magnetograph applications, logical blocks, abacus, film-strip, element-film, etc. In this group there can also be those teaching resources which bring elements of games into learning, and are mostly used for practicing and revision. Classification of school subjects has a specific methodical value when employed in a concrete mathematical situation. 
Innovative resources are, due to dynamic development in technology, widely used, but are methodically insufficiently tested in pedagogical practice. This why they will be grouped into basic and auxiliary resources and their methodical function in the organization of mathematics teaching process will be emphasized. These resources are for the most part arbitrarily interpreted in theory and named in practice. This has a negative effect on their methodical value.

Basic innovative resources are: slides, filmstrips, overhead transparencies and educational software created for mathematics teaching. Average effect of these resources depends on the kind of perception they engage.

For example, audio-resources have an effect of $10-30 \%$, visual ones $30-50 \%$, audio-visual resources $50-70 \%$. The methodical message is clear, there is a need for greater investment in use of audio-visual resources, but is must be noted that this does not apply for mathematics teaching. The most common teaching aids are: blackboard, chalk and numerals. That is one of the reasons why mathematics does not contribute to education as much as it can and should in lower elementary education.

Auxiliary innovative resources are: episcope, overhead projector, cinema-scope, computer, and other technical devices and appliances for visual projections of tasks, lines, images, shapes and similar pedagogical content for mathematical education of students. Methodical role of these auxiliary resources is far less than that of teaching resources, but is not negligible.

\section{Methods of work in introductory mathemat- ics teaching}

The primary feature of methods in introductory mathematics teaching is activity of participants in the teaching process, that is, teacher and students. For mathematics in lower elementary mathematics, the choice falls upon those methods which are best suitable for the nature of the subject matter, students' age and teacher's affinities.

According to this methodical criterion, mathematics teaching is amiable to all variants of verbal-textual and demonstrative-illustrative groups of work methods.

Verbal-textual methods for their cognitive basis have spoken or written word. Word, as a gno- seological-methodical basis should be appropriate and deliberate according to mathematics subject matter and lower elementary students' ability to understand it. This group of teaching methods consists of: method of verbal presentation, method of conversation and method of text manipulation.

Method of verbal presentation is a manner of work in which the teacher (and occasionally students) exposes students to the content of what is being learned. It is based on verbal communication between participants in the work process and is one of the oldest teaching methods. In practice, it is noticed in several forms:narration, describing, explaining and lecturing. Considering the nature of mathematical content in introductory mathematics teaching, this method is mostly used in the form of explaining. It serves to explain the content of mathematical concepts, mathematical symbols and terms, procedures for oral and written calculation, processes of solving tasks, manners of rendering geometrical drawings. "Explaining is communication the aim of which is to capacitate someone for understanding something they did not understand or know." It is a procedure through which students become familiar with new subject matter, and its main purpose is understanding, revealing and perceiving conceptual content of mathematical symbols, terms, processes, operations and gaining insight into their meaning.

Method of conversation represents mutual effort between students and teacher, which takes place in the form of questions and answers. These are formulated by both students and teachers, in a way that teacher's questions are always directed towards students, while students pose questions also among themselves, student to student.

As opposed to the method of presentation, which is a monologue in character, method of conversation is a dialog, because it is based on conversation between participants.

Conversation, more than presentation, invokes thought activity in students and activates attention. Conversation is suitable for assessing whether students have understood and mastered the subject matter. By posing questions to students, teacher estimates students' knowledge of certain teaching subjects, as well as whether there are, and of what sort, possible blanks in their knowledge. 
Method of conversation appears in various forms, of which the most suitable form for the needs of introductory mathematics teaching is the socalled heuristic, discovery-type conversation. By posing questions heuristic in nature, students are lead to perceive that which is equal in a set of examples, and could not be discovered without such an answer. This is why this method is mostly used where the above-mentioned condition exists, primarily in practicing and checking students' homework.

Method of text manipulation is a manner of gaining knowledge and developing abilities through work with text. In introductory mathematics teaching, texts used are: student's book, teaching cards, collection of mathematical problems, or any other suitable texts with mathematical content. Text manipulation is a universal procedure of acquiring information, and therefore it should be nurtured even in introductory mathematics teaching. Working with a text with mathematical content may vary: acquiring numerical data, introducing descriptions of performing calculating operations or geometrical drawings, introducing subject content, generalization of rules, definitions, solving different calculus problems found in the text, etc.

Though the use of text, a habit is created to use books, that is, text as a source of knowledge, an understanding about the function of textbook is formed, as well as consciousness about the fact that one can find out what they do not know from a book. Apart from students, teacher also commonly uses texts with mathematical content while preparing for class, processing new subject matter, practicing and revising. While preparing for class, the textbook enables appropriate dimensioning of teaching unit content, establishing connection with previous and following studying and familiarizing with concepts and formulations that students should master.

Demonstrative-illustrative methods have the exemplar as cognitive basis. Exemplar as gnoseological-methodical fundament may be an object, phenomenon, condition, picture, projection, symbol, pattern, etc. if suitable for cognition of mathematical values. All exemplars are used in the form of demonstration and illustration.

Method of demonstration is a manner of teaching which is conducted through pointing out (showing) and observing. It includes two aspects: pointing out (mostly activity of the teacher) and observing (activity of students).

This method is used in all those situations when various objects, activities, processes etc. are being introduced. In introductory mathematics teaching, different teaching resources are demonstrated, such as didactic materials (plastic slates, sticks, rocks etc.), models of geometrical figures (cube, ball, cylinder), different gauges for measuring length (wood one meter high), surface (square meter of paper), volume (liter), mass (scale), time (hour). Also demonstrated are different graphic presentations (pictures, graphs, diagrams), applications on magnetograph or flannel-graph, element-film, filmstrip. Demonstrated resources serve as aid in mastering mathematical content.

Illustration presents clearly analyzing certain matter in order to understand a particular mathematical dimension. It can be verbal, with the help of adequate mathematical expressions, or illustrative, with the help of adequate symbols, outlines, schemata, projections and other visual expressions in teaching mathematics and geometry. Through assimilation of illustrative and verbal expressions, the students' thought process is intensified.

\section{Evaluating students' success in introductory mathematics teaching}

Evaluating students' success is methodical preparation for grading them in methodology. This obligation cannot be performed during special classes since it involves extraordinary psychological and physical effort and sensitivity of lower elementary students. Grading students in mathematics is performed continuously within teaching, affirming and revision of mathematics subject matter.

This type of realization of educational process is a very complex and delicate teacher's obligation, for there is the question of various pedagogical content and sensitive ages of lower elementary students.

In order to achieve success in this sense, the teacher must take into account principles of grading (publicity, continuity, versatility); components of grading (knowledge, thought process, working-technical activity) and types of grading (combination of subjective and objective evaluation). 
Basic principles of evaluating and testing are: publicity, continuity and versatility. Public evaluation is in accordance with principles of democracy in society. Therefore, the grade should be publicly announced, provide explanation and docket. Students should realize that every activity in teaching is evaluated and graded. Versatile evaluationis grading of knowledge, thought process and working-technical activity, as well as considering interest, investment, ability and working conditions of the student.

Basic components of evaluating and grading are knowledge, thought process and working-technical activity, and additional components are level of interest, investment, ability and working conditions of the student. According to the basic components, a grade is given, while methodical correction of the grade is performed according to additional components. Knowledge is evaluated according to volume, richness and factual characteristics. Thought process is evaluated in accordance with prominent abilities for describing, comparing, selection, deduction, systematization and data generalization.

Working-technical activity is assessed throughbespoken elements of accurate perception, skillful handling of pre-concerted combination of materials and equipment.

Basic types of testing and evaluating are subjective and objective. Subjective evaluation depends for the most part on the teacher's impressions. Objective evaluation depends on the value of tasks of objective type.

\section{Role and significance of homework in introduc- tory mathematics teaching}

Students' homework presents a part of class-work. They stem from teaching and class-work itself and re-engage within it again in various moments of the teaching process, in different forms.

Students' homework has a multiple role. First and foremost, it represents individual work, individualize students in the process of gaining knowledge, as well as provide necessary preparation for life; homework serves to fortify knowledge and rehearse habits, and then the acquired knowledge is applied. Homework presents preparation for upcoming work at school; it also has a special pedagogic assignment, which consists of developing in students a feeling and responsibility for the tasks that are put before them, diligence, organization skills, etc.

One of the most important characteristics which should be developed in students is the feeling for obligations: for example, a first-grade student experiences difficulties while doing homework, but does not seek help, which means that he/she is assertive in work because he/she knows that he/she cannot come to class in front of the teacher without the homework.

Homework is an amenable form of work because it helps building a personal style of work. Every student is an individual and it is not advisable to obtrude him/her with a uniformed manner of work. The opportunity to influence nourishing an aesthetical relation toward work should not be neglected, since a person's taste is measured by beauty.

It is necessary to capacitate students for homework, which is an activity that takes place as early as in the first grade. Capacitating students for individual work is conducted during regular classes while they are directly supervised by the teacher. As the student works individually, he/she becomes more independent in work, and, as homework is at the same time individual work, the teacher should constantly insist on the students' individuality.

Homework may have different aims: to rehearse and solidify acquired knowledge, skills and habits, to systematize and generalize knowledge, skills and habits, to prepare students for work in the following class, and all this has its root in classes. They can have various contents. They may encompass solving numerical problems, which has a goal to exercise procedures of an arithmetic operation, numeric technique, solving tasks verbally, where students apply their calculus knowledge, knowledge of mathematical operations, they practice drawing conclusions, etc.

Homework may be individual and group work. If one group of students performs a task which is a part of a joint problem, then we are talking about group homework, which contributes to educating students about collectivism, as well as forming a feeling of responsibility for completing the task. While assigning homework, the teacher must take into account the volume and difficulty of tasks. If tasks are too difficult, students lose belief in their abilities and instantly seek help from their family members, which takes away the basic significance of homework. 
Homework should also not be too easy and not cause mental effort and endeavor to overcome difficulties. Students perform these kinds of tasks effortlessly, mechanically and disinterested. It is of great importance to be familiar with abilities of one's students, their work pace, home situation, etc. Sometimes it is necessary to make homework differentiated, either according to shortcomings of certain groups or to abilities of individuals.

It is necessary to carefully delimitate the volume of homework. In an experiment, as claimed by Selmir Gorušanin, conducted with thirdgrade lower elementary students, they were given homework of different volume: a) onetwo tasks; b) about five tasks; c) no homework. Upon analysis it was established that students who were assigned five tasks for homework, and this kind of homework is considered voluminous, achieved overall results similar to those of students who never had homework. The best results were noticed with students who had one-two tasks or small-scale homework. This leads to show that it is better to give smallscale homework, while apart from those onetwo tasks it may be recommended that students on a facultative basis perform more tasks. The same author claims that small-scale homework has many advantages, such as: higher possibility of individual completion, ability to complete other obligations etc. (Gorušanin, 1979, p. 31) In elementary school, this is easier to achieve in lower grades. Great homework volume shortens the students' spare time. This means that the teacher must pay attention to the students' free time, relaxation and fun.

In normal conditions in Bosnia and Herzegovina, and according to recent results, it is recommended that duration of doing homework does not surpass:

in the I and II grade $1 / 2$ to 1 hour, and in the III, IV and V grade $1 \frac{1}{2}$ hour.

This does not necessarily apply for every student; some students will require exactly this amount of time, others less, and some of them more. This is why it is important to consider the class average, even particular students. The extent of homework will depend on how much the teacher knows their class and they will accordingly assign homework, while certain details about students can be found out through parents.

Nowadays, the homework system places so much burden on students, that it exceeds all allowed limits. Piling up homework verbally and in writing basically means transferring classroom work from school to home, thus doubling or tripling students' working time. Teachers are often forced to do this due to objective difficulties (reduced working hours, several schools in the same building, a great number of students, etc.). A question is posed: which measures should be taken in this situation? Is there a possibility to come up with a solution which would unburden students while not damaging their general education?

There are possibilities which consist of the following:

a) reduce homework in difficulty as well as in the number of tasks, i.e. duration for completing them;

b) systematic, but planned homework assignment.

\section{Assessing homework and the role of parents in its realization}

Scanning children's homework by parents has many positive sides. A written grade provides great pleasure for the student. It is simultaneously a reword for effort. A child will happily go home with a decision to do the following homework even better. Regularly giving grades to children also affects parents, since it serves as an incentive for them to proof-read the child's homework, and releases them from possible house duties.

Homework with an excellent grade is praised by parents, which gives children even more motivation to pay more attention to homework. Students who have not completed their homework a date is written with a note that homework was not done, and below an insufficient grade. This distresses student's consciousness about responsibility and the parent will also react to irresponsibility.

This grade includes the outlook of the task, alongside with other elements. A weak grade will compel the student to do their homework next time.

If the case occurs where a group of errors is found in homework, additional work is necessary, since this is an obvious sign that students did not understand the presentation of the subject matter or teacher's instructions. 
The teacher must constantly follow the progress of each student, offer help if it is necessary and encourage students to perform homework tasks as accurately as possible. While evaluating homework it can be noticed that tasks are done for students at home by their older siblings, or even parents.

\section{Negative attitude toward homework}

The quality of students' knowledge largely depends on proper organization of their homework, accurate methodical procedures while assigning and employing them. The causes of formalism in students' knowledge can be traced to inaccurate methodical procedures in the area of homework. Some of the major causes will be indicated.

Firstly, it should be mentioned that there are cases where teachers underestimate this form of work, thus employing it too little or even not at all. Formation of such attitude in teachers was influenced by teachings of certain representatives of activity-school, who negated the value of homework for students, denied students' ability for individual work, while forbidding homework for the sake of health protection, freedom and rights of children. In this sense, Ellen Key posed a very determinate attitude. Hugo Gaudig fights for free spiritual work in school environment, bat is very critical regarding students' homework. It is interesting that such an extremist course regarding emphasis on individual work and students' individuality in general, such as Dalton-plan, negates the value of homework. On the other hand, some limit homework, as well as classes, to voluntary students' work, where there is no assignment-giving or forcing students to perform them. (http://www.google.ba/url?sa $=$ t\& $\mathrm{rct}=\mathrm{j} \& \mathrm{q}=\&$ esrc $=\mathrm{s} \&$ source $=$ web $\& \mathrm{~cd}=2 \& \mathrm{ved}=0 \mathrm{C}$ CQQFjAB\&url=http $\% 3 \mathrm{~A} \% 2 \mathrm{~F} \% 2 \mathrm{Fwww} . z w r x$. pondi.hr\%2FDidaktika\%2FDidaktika\%2520$\% 2520$ Dragec.doc\&ei=kXw3UP_wEvPN4QSIwYGIDQ\&usg=AFQjCNHUEF7 $\mathrm{xVjdxqvv}$ ETwCXB5Xt4SQ74A\&sig2=x0wLlw85igzi0CF 77DTlzw)

It is obvious that such an improper and negative attitude of teachers toward homework reflects as a lower knowledge quantum in students, weaker quality of knowledge (i.e. knowledge is not permanent and within formalism of students' knowledge). Not employing homework in teaching means renouncing great opportunities for knowl- edge solidification, rehearsing skills and habits, and very importantly, renouncing the possibility for students to individually apply their knowledge, connect theory and practice and conduct certain practical work. All these actions impede the appearance of formalism in students' knowledge. When there is no homework as part of teaching, students rarely have the opportunity to apply acquired knowledge through conscious activity while solving various problems, to individually observe objects and phenomena, to conduct practical work and experiments, to make different objects and teaching aids, to express acquired knowledge in a variety of ways.

Negative attitude toward students' homework cannot be justified by the fact that conscious activity of students should be expressed throughout the entire teaching process, not only through homework. The point is not to transfer students' conscious activity onto the area of homework, but rather to expand it from classes to homework. To remove homework from the teaching process would mean to mutilate teaching, to consciously denounce one form of students' work, a form of work which cannot be completely replaced by anything, while it can, if properly organized, greatly inhibit formalism in students' knowledge. The cause of formalism in students' knowledge can also be found in the fact that certain teachers do not employ homework as activity, or they do, but insufficiently. The second group of causes encompasses teacher's inaccurate activities involving students' homework, which is the result of incorrect understanding of tasks/problems and didactic possibilities of homework.

\section{METHODOLOGICAL APPROACH}

\section{Previous research}

Through analyzing pedagogical literature, it can be noticed that homework was a current theoretical and practical problem in lower elementary teaching. Its core, place, significance and role in teaching, pedagogy and education in general were emphasized. The specificities of students' work regarding homework, its content and types were elaborated upon. Upsides and downsides were analyzed, norms were determined for doing homework through different ages in elementary school, the manners of giving and controlling homework were written about. 
Theoretically, it was claimed that the upsides of this teaching activity are: individuality in work, advancing according to individual pace, capacitating students for individual work, but also there were downsides: burdening students with homework, incapacity for individual work, difficulties in everyday control, etc. In practice, there were situations where students spend the same amount of time doing homework, as they spend in classes.

\section{Subject and problem of research}

If the starting point is to be the subject of research, it is necessary to provide the definition of the very notion of 'homework', which implies completing work obligations that students have toward school and family, and is done at home.

One portion of homework refers to completing tasks at home.

Dr. Filipović emphasizes in his 'Didaktika' ('Didactics') (1980) that homework should include from 30 minutes for first grade to 2 hours in high school.

Educative workers often wander in the field of assigning homework, which is commonly formalistic and unchecked, without personal engagement in reviewing and marking homework.

For this reason, there are cases in higher elementary classes where students are burdened with homework more than in previous grades because of teacher's pure 'selfish' reasons, who emphasize that their subject is important. They assign homework in their school subject regardless of others. A teacher must take into account students' free time, relaxation and entertainment. Also, while assigning homework, teacher should pay attention to home environment of children.

\section{Aim of research}

The aim of this research is to ascertain and analyze the level of students' exertion with homework. The research will establish the level of connection between students' exertion with homework and their motivation to learn the subject matter, as well as students' optimal exertion with homework.

\section{Research problems (tasks)}

Requirements of every research demand setting certain tasks through the work, in order to avoid divagation and to render every piece of work, bounded by certain problems, valuable precisely within the frame of those problems and demands set before them.

Bearing this in mind, the following problems have been the starting point of this research:

1.To determine the level of connection between temporal exertion of students with homework within a week and students' exertion with homework prescribed by pedagogical norms.

2. To determine the level of participation of parents in helping students complete homework.

3.To determine the level of connection between differentiation of homework and students' motivation to do homework.

\section{Basic hypothesis}

In initial mathematics teaching, homework has a significant role in the process of learning and teaching mathematics.

\section{Sub-hypotheses}

H1: Teachers regularly assign homework.

$\mathrm{H} 2$ : There are significant differences in the volume of homework.

H3: Teachers have different attitudes toward homework.

H4: There are differences in evaluating homework.

\section{Research methods}

In this research, the method of theoretical analysis andthe descriptive method were used in order to gain data necessary for solving this problem. The method of theoretical analysis employs mostly deduction as logical-methodological procedure in pedagogical research. The basis for its application represent already ascertained pedagogical and other cognitions, expressed generally (notions, legitimacies, theories, etc.) gained through the use of other research methods and procedures. The importance of its application lie in its ability to perceive complex aspects of pedagogic realities, deduce significant characteristics and interrelations, as well as legitimacies of development of pedagogical phenomena. Sources for this method include pedagogical literature, as well as text-books in this field of expertise, research related to general social attitudes regarding pedagogy and education, and an existing corpus of scientific knowledge gained through empirical, but also theoretical scientific procedures. 
This method is important while formulating research hypotheses, but it also bears significance while interpreting research results.

The descriptive method enabled gathering, editing and comparing data gathered during research. The core of descriptive method in pedagogical research consists of describing pedagogical phenomena. Their description familiarizes the researcher with them. Only through familiarization with characteristics of a phenomenon is possible to approach examination of causes and connections between phenomena. (Banđur \& Potkonjak, 2002)

\section{Techniques and instruments of research}

Research techniques enable organized, systematic and planned arrival to the set aim. In the framework of research technique there are appropriate tools, i.e. instruments of research, whose purpose is identification, gathering and measuring scientifically based facts. (Banđur \& Potkonjak, 2002)

During realization of this research, techniques of survey and content analysis were used. When it comes to instruments, individual questionnaires (survey papers) for teachers and students and interviews for parents were used.

\section{Sample and statistical data}

The research was conducted in May 2012 in Elementary school 'Travnik'. The survey was conducted on a sample of 14 teachers and 219 students (II grade - 65 students, III grade 82 students and IV grade -72 students), while 105 parents were interviewed via method of random choice.

The student sample used for research is a simple random sample. The basic characteristic of a simple, random sample is equal possibility that all students will be satisfied with the homework the teacher assigns to them.

\section{RESEARCH RESULTS}

Teachers were posed closed-type questions. Research results were systematized and presented tabular. The questions are provided systematically, as well as possible answers and answers to posed questions, followed by tabular presentation (numeric and percentual).

- The first question for teachers was:

- When do you assign homework?

a) after every class

b) after presentation class

c) sometimes

Possible answers were $\mathrm{a}, \mathrm{b}$ and $\mathrm{c}$.

\begin{tabular}{cccc}
\hline Answers & $\mathrm{a}$ & $\mathrm{b}$ & $\mathrm{c}$ \\
\hline Number of answers & 11 & 2 & 1 \\
percentually & $78 \%$ & $15 \%$ & $7 \%$ \\
\hline
\end{tabular}

This means that, according to answers to the question above, $78 \%$ of examinees give homework after every class, $15 \%$ after presentation class, and $7 \%$ of examinees assign homework sometimes.

This confirms the first sub-hypothesis: teachers regularly assign homework.
The second question for teachers was:

- How many tasks do you assign for homework?

a) 5 -7 tasks

b) $3-5$ simple tasks

c) up to 3 more complex tasks 
Possible answers were $\mathrm{a}, \mathrm{b}$ and $\mathrm{c}$.

\begin{tabular}{cccc}
\hline Answers & $\mathrm{a}$ & $\mathrm{b}$ & $\mathrm{c}$ \\
\hline Number of answers & 2 & 7 & 5 \\
percentually & $15 \%$ & $50 \%$ & $35 \%$ \\
\hline
\end{tabular}

This means that $15 \%$ of examinees assigns $5-7$ tasks, $50 \%$ give $3-5$ simple tasks and $35 \%$ of examinees assigns up to 3 more complex tasks. The second sub-hypothesis is also confirmed: there are significant differences in the volume of homework.
The third question for teachers was:

-When do you review homework?

a) cursory, at the beginning of every class

b) at the beginning of every class I only note if homework was done

c) occasionally in detail at home

d) every day cursory, sometimes detailed.

Possible answers were $\mathrm{a}, \mathrm{b}$ and $\mathrm{c}$.

\begin{tabular}{ccccc}
\hline Answers & $\mathrm{a}$ & $\mathrm{b}$ & $\mathrm{c}$ & $\mathrm{d}$ \\
\hline Number of answers & 5 & 0 & 5 & 4 \\
percentually & $36 \%$ & $0 \%$ & $36 \%$ & $28 \%$ \\
\hline
\end{tabular}

This means that $36 \%$ of examinees review homework cursory and $36 \%$ occasionally in detail at home, while $28 \%$ presents combination of both answers.

The third sub-hypothesis is confirmed as well:teachers have different relations toward homework.
The fourth question for teachers was:

- I evaluate homework

a) qualitatively

b) quantitatively

c) both qualitatively and quantitatively

Possible answers were $\mathrm{a}, \mathrm{b}$ and $\mathrm{c}$.

\begin{tabular}{cccc}
\hline Answers & $\mathrm{a}$ & $\mathrm{b}$ & $\mathrm{c}$ \\
\hline Number of answers & 1 & 0 & 13 \\
percentually & $7 \%$ & $0 \%$ & $93 \%$ \\
\hline
\end{tabular}

This means that $7 \%$ of examinees evaluate homework qualitatively, and $93 \%$ both qualitatively and quantitatively.

The fourth sub-hypothesis is confirmed: there are different evaluation styles of homework.

\section{Analysis of results of students' questionnaire}

The questionnaire was assembled in order to collectively examine students' interest for homework.

Answers to questions are represented tabular, individually by grades, and finally summarized. 
This examination instrument will serve to ascertain the students' affinity through certain interest in homework, the way they fulfill obligations toward work, or simply, what is their relation toward homework.

Questions from students' questionnaire:

1) Does it take you a long time to do homework?

2) Does anybody help you to do homework?

3) Are there tasks especially given to excellent students?

II grade, total of 65 students
4) Are there tasks especially given to weaker students?

5) Do you have homework for more than two subjects a day?

6) How many minutes do you spend on doing mathematics homework?

a) up to 15 minutes; b) 15 - 30 minutes; c) over 30 minutes

Possible answers to the first five questions are yes or no, and in the sixth question $\mathrm{a}, \mathrm{b}$ or $\mathrm{c}$.

\begin{tabular}{ccccc}
\hline Question No. & YES & $\%$ & NO & $\%$ \\
\hline 1. & 34 & 52 & 31 & 48 \\
2. & 47 & 72 & 18 & 28 \\
3. & 6 & 9 & 59 & 91 \\
4. & 8 & 12 & 57 & 88 \\
5. & 22 & 34 & 43 & 66 \\
\hline
\end{tabular}

III grade, total of 82 students

\begin{tabular}{ccccc}
\hline Question No. & YES & $\%$ & NO & $\%$ \\
\hline 1. & 41 & 50 & 41 & 50 \\
2. & 35 & 43 & 47 & 57 \\
3. & 15 & 18 & 67 & 82 \\
4. & 55 & 67 & 27 & 33 \\
5. & 65 & 79 & 17 & 21 \\
\hline
\end{tabular}

IV grade, total of 72 students

\begin{tabular}{ccccc}
\hline Question No. & YES & $\%$ & NO & $\%$ \\
\hline 1. & 45 & 62 & 27 & 38 \\
2. & 12 & 16 & 60 & 84 \\
3. & 32 & 44 & 40 & 56 \\
4. & 52 & 72 & 20 & 78 \\
5. & 64 & 88 & 8 & 12 \\
\hline
\end{tabular}


The sum total of positive and negative answers from 219 surveyed students:

\begin{tabular}{ccccc}
\hline Question No. & YES & $\%$ & NO & $\%$ \\
\hline 1. & 120 & 55 & 99 & 45 \\
2. & 94 & 43 & 125 & 57 \\
3. & 53 & 24 & 166 & 76 \\
4. & 115 & 53 & 104 & 47 \\
5. & 151 & 69 & 68 & 31 \\
\hline
\end{tabular}

Answers to the sixth question:

\begin{tabular}{lcccccc}
\hline \multicolumn{1}{c}{ Grade } & \multicolumn{2}{c}{ II } & \multicolumn{2}{c}{ III } & IV \\
\hline No. of students and & 65 & $\%$ & 82 & $\%$ & 72 & $\%$ \\
percentage & & & & & & \\
a) up to 15 minutes & 19 & 29 & 34 & 41 & 25 & 35 \\
b) $15-30$ minutes & 34 & 52 & 37 & 45 & 17 & 24 \\
c) over 30 minutes & 12 & 19 & 11 & 14 & 30 & 41 \\
\hline
\end{tabular}

This table makes it obvious that out of 219 surveyed students, 78 or $36 \%$ of them spends up to 15 minutes doing homework; 88 or $40 \%$ of students spends 15 - 30 minutes; while 55 or $24 \%$ spend over 30 minutes doing homework. Thus, the conclusion follows that students do not spend a lot of free time completing mathematics homework, even though more than half of them claim that they invest a lot of time doing homework.

When comparing gathered results according to grades, it is visible that answers to some questions digress depending on the grade, while some are very similar. It can be concluded that lower-grade students ask more help while doing homework, they have less than two types of homework a day, and that teacher's demands increase when compared to higher grades.

The questionnaire also shows that students are mostly assigned the same tasks for homework, while in higher grades there is increased care about weaker students.

This survey cannot provide accurate status in schools and precise description of dealing with homework, since this varies from teacher to teacher, but it is interesting to present and compare the answers of interviewed parents.
The questions were answered by 105 parents, with the following results:

1.Do you believe that your child is overburdened with homework?

Answers: yes by 32 or $30 \%$ of parents, no by 73 or $70 \%$ of parents.

2.Do you help your child with homework?

Answers: yes by 53 or $50 \%$ of parents, no by 28 or $27 \%$, sometimes 14 or $13 \%$ of parents.

3 . Should a pedagogical norm be set, by which the time for doing homework would be determined?

Answers: yes by 21 or $20 \%$ of parents, no by 84 or $80 \%$ of parents.

All this data shows that parents want more for their children, while children (students) want less.

\section{CONCLUSION}

Based on research and upon analysis of acquired data, the following conclusions can be drawn:

- Students' homework still has an extremely significant place in learning in introductory mathematics teaching;

- There are certain differences in the volume, quality, structure of homework in introductory mathematics teaching; 
- With teachers, there is still a presence of reduced, narrow-minded outlook on homework, so some teachers believe that homework is or is not necessary;

- There are differences in evaluating homework;

- Parents who believe that homework should be given, that it is good and useful for their children ascribe great value to homework.

Demand against long-lasting, exhausting homework is difficult to elaborate upon, until the real state of affairs in practice is examined. This problem exists, but many do not wish to admit it.

A lot is needed, more is given, and too much is asked. Homework, in the sense which defines it, with precisely pedagogically defined tasks and reasonable and optimal time for work - YES. Homework which exhaust the child, degrades, psychologically burdens, places time limitations - NO. That form of homeworkshould not exist, and the sooner it is rooted out, the better. Having in mind the significance, methodic and educational aims that should be fulfilled through homework, as well as certain portrayed elements here, which significantly influenced the present fairly weak quality of students' homework, the obligation of teachers and parents as well would be to put in more effort and take measures in order to amplify responsibility of all students toward their duties.

\section{REFERENCES}

Banđur, V. and Potkonjak, N. (2002). Istraživanje u skoli [Research in the School]. Serbia,Užice: Učiteljski fakultet.

Filipović, N. (1980).Didaktika [Didactics].B\&H, Sarajevo: Svjetlost.

Gorušanin, S. (1979). Priručnikza nastavnike (uz udžbenik matematike za drugi razred osnovne škole) [Manual for Teachers]. B\&H, Sarajevo: IGKRO "Sarajevo"-OOUR Zavod za udžbenike.

Markovac, J. (1992). Metodika početne nastave matematike [Methodics teaching basic mathematics]. Croatia, Zagreb: Skolska knjiga.

Tomić, R. and Osmić, I. ( 2006). Didaktika [Didactics]. B\&H, Tuzla: Denfas.

Web sources:

http://uciteljitk.com.ba/Npp.pdf. (Accessed 07/05/2012)

http://www.mycity.rs/Matematika/Znacaj-i-nacin-analize-domacih-zadataka-iz-matematike.html. (Accessed $12 / 05 / 2012$ )

http://www.google.ba/url?sa=t\&rct=j\&q=\&esrc=s\&sou $\mathrm{rce}=$ web\&cd $=2 \&$ ved $=0$ CCQQFjAB\&url $=\mathrm{http} \% 3 \mathrm{~A} \% 2$ F\%2Fwww.zwrx.pondi.hr\%2FDidaktika\%2FDidaktika $\% 2520 \% 2520$ Dragec.doc\&ei $=\mathrm{kXw} 3 \mathrm{UP}$ wEvPN4QSIw YGIDQ\&usg=AFQjCNHUEF7xVjdxqvvETwCXB5Xt 4SQ74A\&sig $2=x 0 \mathrm{wLlw} 85$ igzi0CF77DTlzw $($ Accessed $12 / 05 / 2012$ ) 